\title{
ПЕРСПЕКТИВЫ РАЗВИТИЯ ГОСУДАРСТВЕННЫХ И МУНИЦИПАЛЬНЫХ ЗАКУПОК НА РЫНКЕ ИНТЕРНЕТ-УСЛУГ
}

\author{
(c) 2020 Плотников Александр Игоревич \\ ассистент Высшей инженерно-экономической школы \\ Санкт-Петербургский политехнический университет Петра Великого, Россия, Санкт-Петербург \\ E-mail: al.plotn@mail.ru
}

В настоящее время в тендерной системе России несмотря на сильный импульс в развитии, наблюдающийся в последние несколько лет, имеются значительные проблемы, тормозящие развитие контрактной системы, и рост экономики страны в целом. Благоприятной тенденцией является цифровизация федеральной и муниципальной контрактных систем, которая позволит решать накопившиеся проблемы и переведет контрактную систему на новый уровень развития. Целью данного исследования является выявление перспективных направлений развития государственных и муниципальных закупок. Рассматриваются инновационные технологии и методы цифровой экономики, в том числе электронные торговые площадки, технологии блокчейн, системы CRM, смартконтракты. Сделаны выводы, что перспективами в развитии государственных и муниципальных закупок на рынке интернет-услуг являются: технологии и методы цифровой экономики, позволяющие автоматизировать большую часть рутинных процессов и максимально исключить человеческий фактор из многих процессов управления закупками; переход от бумажной процедуры закупок к электронной, что позволит сократить временные издержки на протяжении всего цикла закупки, благодаря технологии блокчейн; использование интернет-услуг, что позволит убрать избыточную административную нагрузку и систематизировать существующую на данный момент административную базу и на программном уровне закрепить требования и правила проведения государственных закупок. Актуальность данного исследования обусловлено тем, что осуществление государственных и муниципальных закупок на рынке интернет-услуг позволит снизить коррупционную и бюрократическую составляющие контрактной системы, оптимизировать время осуществляемых операций, тем самым перевести контрактную систему на новый этап развития.

Ключевые слова: государственные и муниципальные закупки; рынок интернет-услуг; тендерная система России; технология блокчейн; цифровая экономика.

Введение: Тендерная система России получила достаточно сильный импульс в развитии в последние несколько лет. Опыт становления российской системы государственных закупок в условиях развития рыночных отношений показал эффективность и перспективность этого направления для экономичного использования финансовых ресурсов и обеспечения качественной продукцией, как государственных потребностей, так и нужд других хозяйствующих субъектов [19]. Однако, несмотря на это, в России до сих пор существуют проблемы работы с тендерами, затруднения при участии в торгах. Основными проблемами, тормозящими развитие современной системы госзакупок в России, являются: недостаточная четкость и унификация технологий, достаточная сложность процедур проведения госзакупок, многочисленные нарушения, связанные с использованием «серых» схем, сговоры при обходе законодательных положений. Решение многих проблем осуществимо посредством внедрения инновационных технологий в сфере информационных и коммуникационных услуг, которые представляют собой движущую силу в условиях глобализации экономики.

В условиях жесткой конкуренции многие субъекты предпринимательской деятельности, частные структуры вынуждены основывать и переходить на электронные рынки, выстраивая новый механизм взаимодействия, основой которого являются прочные и взаимовыгодные партнерские отношения [14]. В тоже время рынок электронной торговли стоит в зоне высокого риска сложности и неопределенности принятия субъектами рыночных взаимоотношений решений в управлении в современных условиях интенсивного развития сети Интернет. Поэтому важно понимать перспективы развития и функ- 
ционирования тендерной системы России в условиях цифровизации экономики.

Вопросами организации и функционирования рынка интернет-услуг занимаются такие ученые как Махноносов Д. В. [14], Горовой А. А. [9], Антипин К. [5], Большаков А. С. [7], Родионов Д. Г. $[10,11,17]$ Вопросы развития государственных и муниципальных закупок затронуты в работах Фролова А.В. [19], Ахатовой А.М. [6], Бреслеpa A.M. [6].

\section{Материалы и методы:}

В научных исследованиях приводится определение понятия электронной торговли как полноценного рынка в сети интернет-услуг, а также системное обоснование применения современного маркетингового инструментария целостного взаимодействия субъектов экономических взаимоотношений в механизме функционирования электронных торговых площадок в парадигме маркетинга взаимоотношений.

Согласно проекта Стратегии развития электронной торговли в Российской Федерации до 2025 года среди форматов электронной торговли можно выделить [20, 21]:

- интернет-торговлю - особенностью данного метода построения процесса продажи является то, что ознакомление с товаром у покупателя и подтверждение намерений его приобретения наступает посредством применения информационно-коммуникационных средств системы Интернет;

- инернет-магазины - проведение процесса купли-продажи, при которой посредником осуществления сделки является торговое предприятие, которое организует сбор и передачу покупателю основной информации о товаре (цена, продавец, способ доставки и др.) и непосредственно доставку его к месту нахождения покупателя.

- интерент-каналы розничной торговли формирование цифровой среды, в рамках которой возможно осуществление заказов потребителями;

- интернет-покупка - выполнение условий договорных отношений между продавцом и покупаетелем с использованием инструментов цифрового контента [20, 21].

Электронная торговая площадка - программно-аппаратный комплекс организационных, информационных и технических решений, обеспечивающих взаимодействие продавца и покупателя через электронные каналы связи (рис.1) [14].

Как правило электронные торговые площадки подразделяются на электронные торговые площадки для государственного и муниципального заказа и электронные торговые площадки для коммерческих торгов.

В теории и практике управление заказами описывается как последовательность процессов, протекающих во времени по определённым

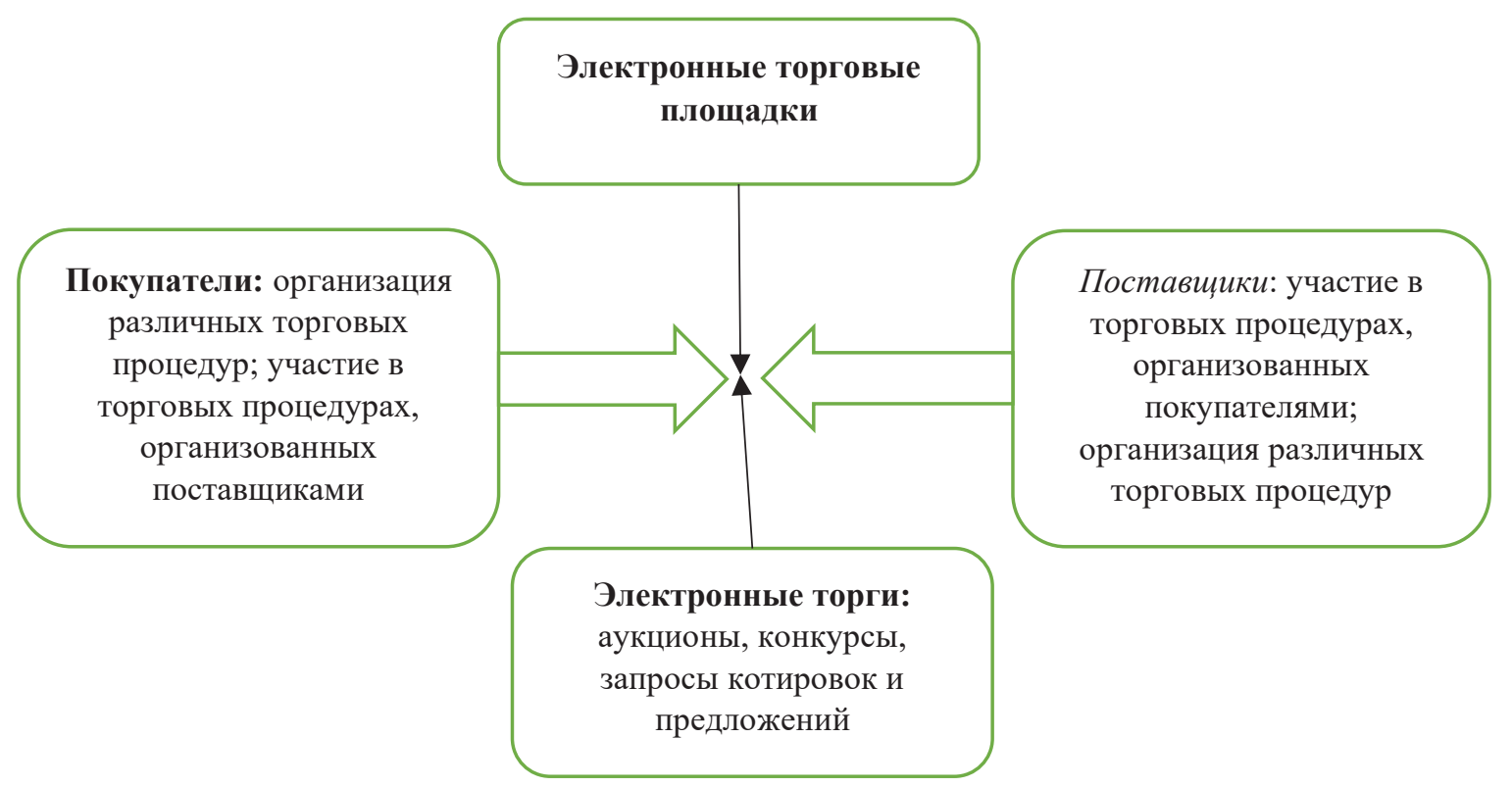

Рисунок 1. Схема взаимодействия субъектов электронной торговой системы. 
временным фазам с начального момента получения заказа и моментом обработки или отработки заказа [9].

Факторы, которые необходимо проанализировать при заказе услуг или пакета услуг: возможные недопоставки; возможные риски; уровень инфляции и рост цен; устаревшие пакеты услуг; неопределенность и колеблемость предложений и спроса на услуги.

Для оценки, анализа и контроля качества совершенствования методов и механизмов управления пакетами заказов и услуг необходимы модели и расчётные методики, которые бы позволяли наблюдать и измерять множество показателей в целом [8]. Заказ на поставку документально (договором или контрактом) оформляется, на основании этих документов. при необходимости, приобретаются необходимые ресурсы, материальные товары и услуги [5]. Достаточно часто оформляется заявка на заказ пакета услуг, если бюджет сервисной организации позволяет выделить определенные суммы денежных средств на работу с контрагентами и поставщиками. В заявке указываются: объект закупки; коды статей расходования денежных средств; фиксируются специфические условия, регулирующие закупку: условия доставки, требования к доставке, отношения с партнёрами по технологиям аутсортинга, свойства и характер поставляемых ресурсов.

Основные функции и задачи в управлении пакетом услуг: определение временной точки заказа или перезаказа услуг; определение возможного минимального и максимального потенциального объёма услуг в пакете; прогнозирование спроса на услуги; определение возможных скидок на приобретаемые объёмы услуг; выявление рисков; объёмы или размеры экономичного пакета услуг и др. [7].

Для управление заказами на сбыт услуг или пакетов услуг обычно используются следующие программные средства и программные модули: управление финансами сбыта услуг, управление формированием ассортимента, управление цепями поставок услуг или пакетов услуг (логистика поставок услуг), управление закупками, управление продажами услуг, управление взаимоотношениями с клиентами (система CRM), управление персоналом, управление информационными и прочими технологиями при сбыте услуг, управление проектами формирования и сбыта пакетов услуг, управление заказами на продажу услуг или пакетов услуг компаниям с мультиатрибутной продукцией, затратные модули и модули ценообразования и др.

Общая схема оперативного управления пакетами заказов и услуг показана на рисунке 3.

\section{Результаты и обсуждение:}

В соответствии с распоряжением Правительства РФ № 1662-p [3] одним из важнейших приоритетов социально-экономического развития страны становится масштабное технологическое обновление экономики благодаря проведению широкомасштабной исследовательской деятельности в инновационном секторе и фор-

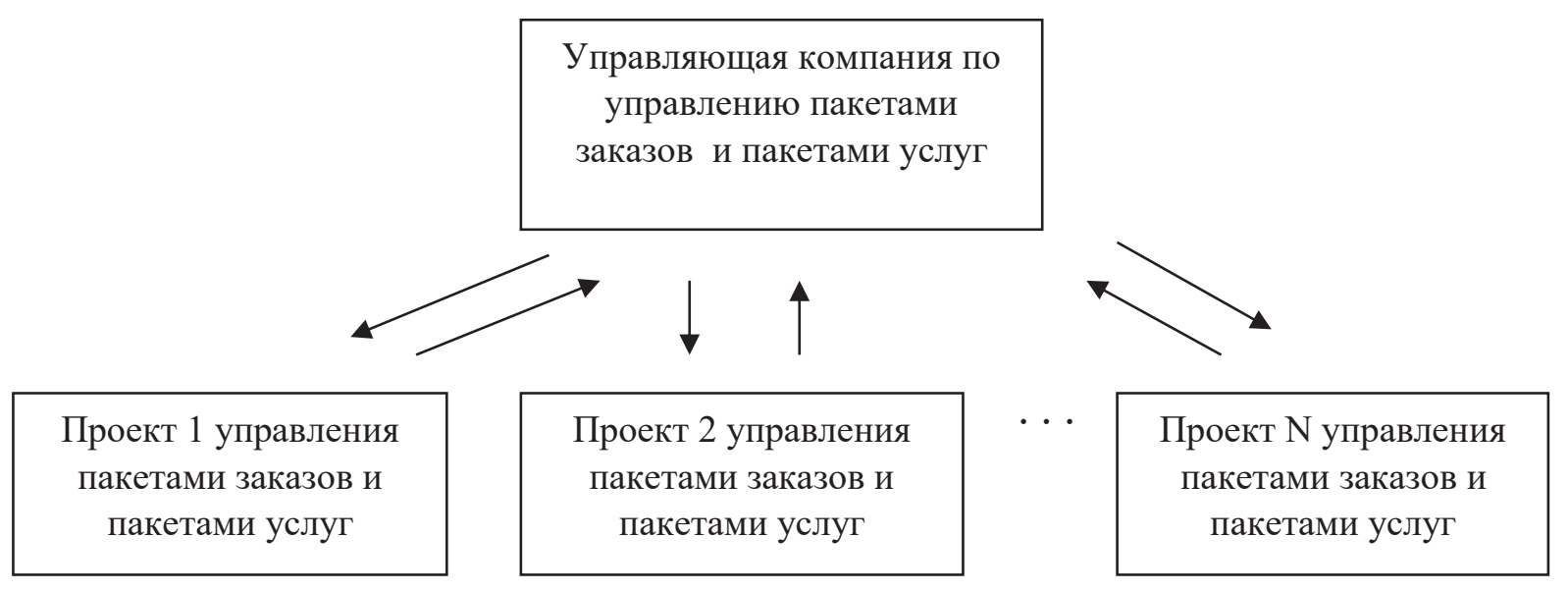

Рисунок 2. Проектная концепция работ с пакетами заказов и услуг с помощью центральной управляющей компании (стрелки вниз - заказы на проект, стрелки вверх - отчёты о проведённых работах и сбыте пакетов услуг, по показателям) [10] 
Внешние факторы среды, влияющие на потребление услуг, количество заказов, поведение конкурентов и других агентов потребительского рынка

\begin{tabular}{|c|c|c|}
\hline$\nabla$ & $\downarrow$ & $\downarrow \uparrow$ \\
\hline $\begin{array}{c}\text { 1. Формирование } \\
\text { портфеля или } \\
\text { пакета заказов и } \\
\text { услуг }\end{array}$ & $\begin{array}{c}\text { 2. Организация и } \\
\text { реорганизация, } \\
\text { реализация работ по } \\
\text { планам и бюджету } \\
\text { сбыта услуг }\end{array}$ & $\begin{array}{l}\text { 3.Контроль, учёт, оценка, } \\
\text { мониторинг динамики } \\
\text { процессов формирования } \\
\text { пакетов и их сбыта, по } \\
\text { оценочным показателям }\end{array}$ \\
\hline \multicolumn{3}{|l|}{4} \\
\hline \multicolumn{2}{|c|}{$\begin{array}{c}\text { 5. Принятие управленческих регулирующих } \\
\text { оперативных решений по диверсификации рынков } \\
\text { сбыта услуг, ассортименту услуг, ценам, скидкам, } \\
\text { организации планирования и процесс управления, } \\
\text { логистики снабжения и сбыта, работе с персоналом } \\
\text { и др. }\end{array}$} & $\begin{array}{l}\text { 4. Анализ организации } \\
\text { управления и } \\
\text { исполнения заказов, } \\
\text { сбыта пакетов услуг, за } \\
\text { периоды времени по } \\
\text { показателям }\end{array}$ \\
\hline
\end{tabular}

Рисунок 3. Адаптивный механизм оперативного управления пакетами заказов и услуг с использованием различных типовых методов анализа и оценок [10].

мированию у субъектов инновационной среды предпринимательской модели поведения, позволяющей увеличить конкурентоспособность России на мировом рынке продажи инновационных товаров, работ и услуг.

Стоит отметить, что одним из направлений развития в рамках стратегии заявлено стимулирование инновационной направленности осуществления государственных закупок и использование системы государственных закупок как поддерживающей среды для российских компаний.

Среди наиболее популярных методов формирования деятельности по осуществлению государственных закупок можно отметить Supply Chain Management. Структура осуществления цепочки поставок заключается в создании среды взаимодействия между фирмами-участниками торговой деятельности. Суть состоит в том, что все фирмы участвуют в цепочке поставок и важным условием становится учет факторов, связанных со сложностью продукта, доступностью сырья и количеством поставщиков. В рамках «цепи поставок» на каждом уровне может быть разное число клиентов и поставщиков. Уровень взаимоотношений в разных частях цепи поставок зависит от координации и интеграции звеньев цепочки [22, 23].
В настоящий момент в российской экономике выделяются три перспективных направления в реализации глобальной реформы в сфере товаров, работ и услуг:

1. Создание контрактной системы закупок для обеспечения государственных и муниципальных нужд;

2. Формирование системы государственного оборонного заказа;

3. Регламентация закупок субъектов и государственного сектора экономики;

4. Ориентация на осуществление государственных и муниципальных закупок на рынке интернет-услуг.

Среди очевидных преимуществ применения электронных торговых площадок при осуществлении регулирования государственных закупок стоит отметить [14]:

- экономию рабочего времени за счет снижения количество операций, связанных с процессом от определения закупки до её оформления;

- возможность честной конкуренции между заказчиками и покупателями за счет прозрачности предоставляемых на цифровой платформе данных;

- возможность участия в торгах все зависимости от территориального расположения субъ- 
ектов торговых отношений;

- доступность платформы для представителей бизнеса, что увеличивает число потенциальных участников на перспективу и повышает качество закупаемых средств для государственных служб за счет более открытой конкурентной борьбы [14].

Функциональные возможности электронных торговых площадок представлены на рисунке 4 .

Принцип осуществления государственного контроля за процессом интернет-торговли заключается в создании среды взаимодействия между участниками торговых отношений благодаря поддержанию равновесия между торговыми сетями и малыми торговыми предприятиями.

Государственное регулирование интернет торговли позволяет устранить негативное влияние недостаточного уровня профессиональной подготовки участников торговых сделок; снизить уровень недоверия потребительского сектора к системе электронных платежей; влияние психологического барьера, связанного с возможностью мошенничества в цифровом пространстве, на процесс проведения торгов.

Понимание особенностей осуществления интернет-торговли способствует более эф- фективному применению существующих технических и организационных инструментов осуществления операций по купле-продаже товаров [20].

Современные возможности осуществления закупочной деятельности в рамках цифрового пространства диктуют необходимость выбора наиболее рациональных методов осуществления электронной торговли, особенно, если закупки ориентированы на небольшие объемы товаров и услуг. При этом, те площадки, которые функционируют в рамках 44-ФЗ зачастую не обеспечивают должный уровень гибкости и не удовлетворяют запросы покупателей и заказчиков в полной мере. Решением данной проблемы может стать использование площадок, созданных в рамках работы 223-Ф3, так как обеспечивают более удобный способ проведения закупок малого объема. Например, небольшие интернетмагазины [15].

Для того, чтобы привлекать покупателей заказчикам следует использовать данные не только открытых источников, но и закрытых, что будет способствовать расширению клиентской базы, кроме того, размещение актуальной информации о технических характеристиках товаров и исследовательской деятельности, свя-

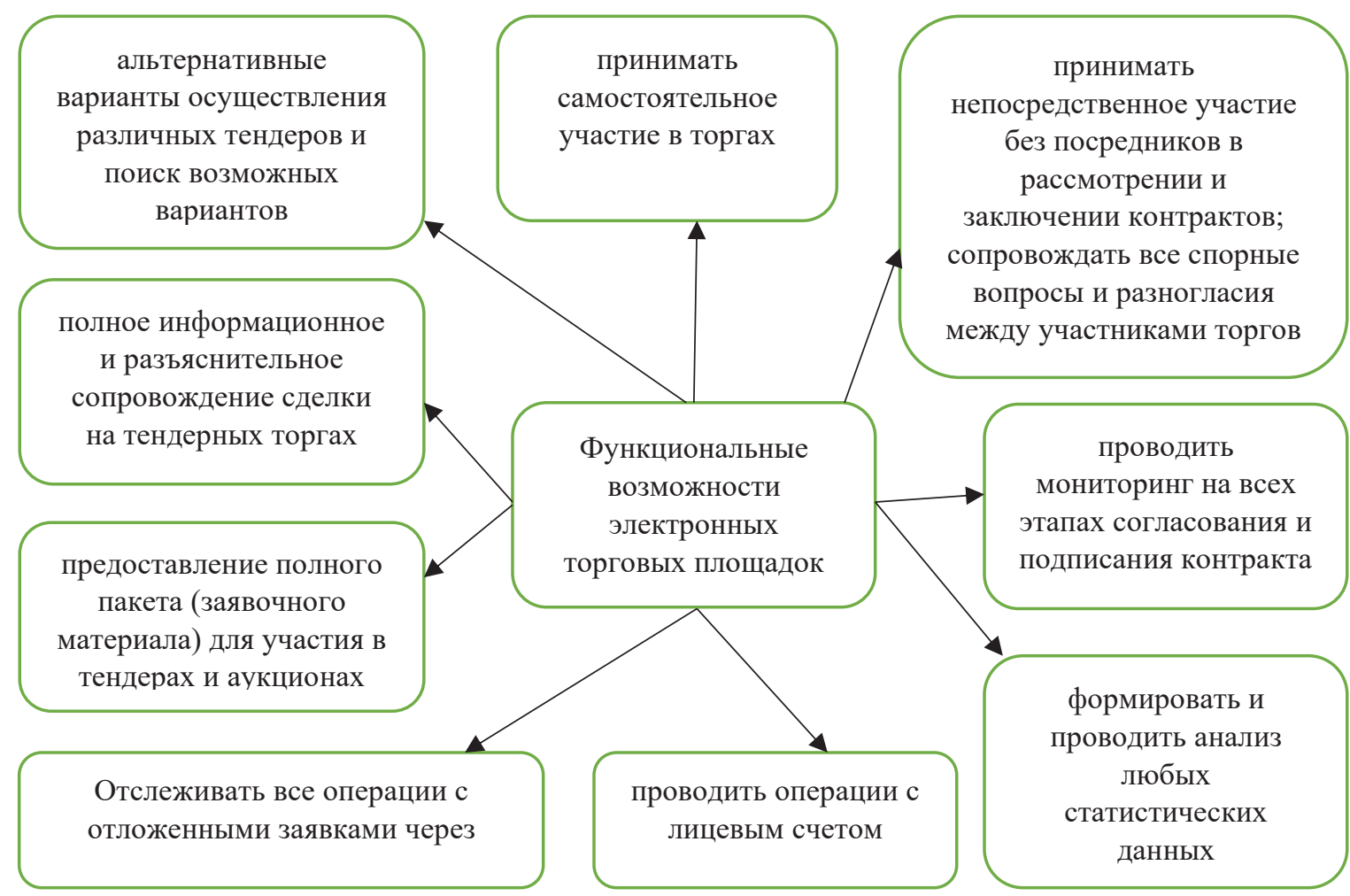

Рисунок 4. Функциональные возможности электронных торговых площадок 
занной с изучением их составляющих, позволит увеличить заинтересованность потенциальных клиентов.

В таблице 1 представлены основные государственные электронные торговые площадки для осуществления государственных закупок, а также и электронные торговые площадки.

Одной из перспективных таких технологий применительно к контрактной системе является: блокчейн (blockchain), данная технология позволяет децентрализовать функции государства и распределить их между всеми членами общества, тем самым повысить уровень доверия населения к государственному аппарату, также технология направленна на максимизацию достоверности информации [6].

Сильное влияние на процесс осуществления государственных закупок оказывает информационная ассиметричность между доступными технологиями и правовой системой включая блокчейн-технологии.

Блокчейн является серьезным вызовом для органов регулирования и участников сделок [12].
Этот факт связан с децентрализованностью и автономностью блокчейн-технологий, а также независимостью от государственных органов, что осложняет процесс надзора и контроля за закупочной деятельностью [13, 15].

Возможностями применения технологии блокчейн в контрактной системе являются [14]:

- сокращение временных издержек на протяжении всего цикла закупки, то есть переход от бумажной процедуры осуществления закупки к полностью электронной процедуре, что в среднем сэкономит в 2 раза больше времени.

- применение смарт-контрактов. Смартконтракты - это электронный алгоритм, подразумевающий выполнение определенных условий, после которых происходит сделка и в результате которой одна из сторон получает заранее внесенную в алгоритм «оплату». Целью смарт-контрактов является упрощение процесса осуществления государственных закупок, снижение издержек и развития механизма контроля исполненных контрактов, а также повышение эффективности управления временными ресур-

Таблица 1. Основные государственные электронные торговые площадки для осуществления государственных закупок.

\begin{tabular}{|c|c|}
\hline $\begin{array}{c}\text { Название электронной торговой } \\
\text { площадки }\end{array}$ & Законодательство РФ \\
\hline $\begin{array}{l}\text { Закрытое акционерное общество } \\
\text { «Сбербанк - Автоматизированная } \\
\text { система торгов» }\end{array}$ & $\begin{array}{l}\text { Федеральный закон от } 5 \text { апреля } 2013 \text { г. N 44-Ф3 } \\
\text { «О контрактной системе в сфере закупок товаров, } \\
\text { работ, услуг для обеспечения государственных и } \\
\text { муниципальных нужд». С изменениями и дополне- } \\
\text { ниями от: } 31 \text { декабря } 2017 \text { г.[1] }\end{array}$ \\
\hline ООО «РТС-тендер» & $\begin{array}{l}\text { Федеральный закон «О контрактной системе в сфере } \\
\text { закупок товаров, работ, услуг для обеспечения госу- } \\
\text { дарственных и муниципальных нужд» от 05.04.2013 } \\
\text { N 44-Ф3 (последняя редакция) [1]. Федеральный } \\
\text { закон «О закупках товаров, работ, услуг отдельными } \\
\text { видами юридических лиц» от 18.07.2011 N 223-Ф3 } \\
\text { (последняя редакция) [2] }\end{array}$ \\
\hline ОАО «Единая электронная торговая площадка» & $\begin{array}{l}\text { Приказ Министерства экономического развития РФ } \\
\text { от } 26 \text { октября } 2009 \text { г. N } 428 \text { «Об утверждении Порядка } \\
\text { отбора электронных площадок в целях проведения } \\
\text { открытых аукционов в электронной форме» [4] }\end{array}$ \\
\hline $\begin{array}{l}\text { ГУП «Агентство по государственному заказу, ин- } \\
\text { вестиционной деятельности и межрегиональным } \\
\text { связям Республики Татарстан» }\end{array}$ & $\begin{array}{l}\text { Приказ Министерства экономического развития РФ } \\
\text { от } 26 \text { октября } 2009 \text { г. N } 428 \text { «Об утверждении Порядка } \\
\text { отбора электронных площадок в целях проведения } \\
\text { открытых аукционов в электронной форме» [4] }\end{array}$ \\
\hline $\begin{array}{l}\text { ЗАО «Московская межбанковская } \\
\text { валютная биржа» }\end{array}$ & $\begin{array}{l}\text { Приказ Министерства экономического развития РФ } \\
\text { от } 26 \text { октября } 2009 \text { г. N } 428 \text { «Об утверждении Порядка } \\
\text { отбора электронных площадок в целях проведения } \\
\text { открытых аукционов в электронной форме» [4] }\end{array}$ \\
\hline $\begin{array}{l}\text { Открытое акционерное общество } \\
\text { «Российский аукционный дом» }\end{array}$ & $\begin{array}{l}\text { Федеральный закон от } 5 \text { апреля } 2013 \text { г. N 44-Ф3 } \\
\text { «О контрактной системе в сфере закупок товаров, } \\
\text { работ, услуг для обеспечения государственных и } \\
\text { муниципальных нужд». С изменениями и дополне- } \\
\text { ниями от: } 31 \text { декабря } 2017 \text { г.[1] }\end{array}$ \\
\hline
\end{tabular}


сами;

- сокращение избыточной административной нагрузки, таким образом, позволяя систематизировать существующую на данный момент административную базу и на программном уровне закрепить требования и правила проведения государственных закупок [14].

\section{Заключение:}

Таким образом, основными перспективами в развитии государственных и муниципальных закупок на рынке интернет-услуг являются:

1. Технологии и методы цифровой экономики позволят автоматизировать большую часть рутинных процессов и максимально исключить человеческий фактор из многих процессов управления закупками;

2. Переход от бумажной процедуры закупок к электронной позволит сэкономить в среднем в 2 раза больше времени, что в свою очередь позволит сократить временные издержки на протяжении всего цикла закупки, благодаря тех- нологии блокчейн;

3. Использование интернет-услуг также позволит сократить избыточную административную нагрузку и систематизировать существующую на данный момент административную базу и на программном уровне закрепить требования и правила проведения государственных закупок.

Таким образом, совокупность современных методов и технологий цифровой экономики позволит значительно автоматизировать процесс осуществления государственных и муниципальных закупок на рынке интернет-услуг, снизить коррупционную и бюрократическую составляющие контрактной системы, оптимизировать время осуществляемых операций, тем самым перевести контрактную систему на новый этап развития.

Дальнейшими направлениями исследования может стать изучение вопроса развития инновационного подхода к осуществлению процесса государственных закупок в электронном пространстве.

\section{Библиографический список}

1. Федеральный закон от 5 апреля 2013 г. N 44-Ф3 «О контрактной системе в сфере закупок товаров, работ, услуг для обеспечения государственных и муниципальных нужд» С изменениями и дополнениями от: 31 декабря 2017 г.

2. Федеральный закон «О закупках товаров, работ, услуг отдельными видами юридических лиц» от 18.07.2011 N 223-Ф3 (последняя редакция).

3. Распоряжение Правительства РФ от 17.11.2008 N 1662-р (ред. от 28.09.2018) «О Концепции долгосрочного социально-экономического развития Российской Федерации на период до 2020 года».

4. Приказ Министерства экономического развития РФ от 26 октября 2009 г. N 428 «Об утверждении Порядка отбора электронных площадок в целях проведения открытых аукционов в электронной форме».

5. Антипин К. Эффективное управление пакетами услуг Построение системы активации услуг для мультисервисных сетей с использованием компонентного подхода // Т-Сomm-Телекоммуникации и Транспорт. 2008. № 2. C. 61-62.

6. Ахатова А.М., Бреслер А. М. Перспективы и тенденции развития федеральной контрактной системы // Молодой ученый. 2019. № 263 (25). С. 266-270.

7. Большаков А.С. Инновации в управлении организациями сервиса: модели и методы оценки эффективности и конкурентоспособности // Экономика и управление. 2012. № 5 (79). С. $70-75$.

8. Горовой А.А., ПлотнИков А.И. МЕТОДИКА ОЦЕНКИ ЭКОНОМИЧЕСКОЙ ЭФФЕКТИВНОСТИ УПРАВЛЕНИЯ ЗАКАЗАМИ И ПАКЕТАМИ УСЛУГ // ЭКОНОМИКА И ПРЕДПРИНИМАТЕЛЬСТВО. 2016. № 77 (12 (2)). С. $886-$ 890.

9. Горовой А.А., Плотников А. И. Современные методы, средства и системы для управления заказами и пакетами услуг // Экономика и предпринимательство. 2017. № 1. С. 802-811.

10. Горовой А.А., Родионов Д.Г., Плотников А.И. Совершенствование механизмов и методов оперативного управления пакетами заказов и услуг // Экономика и предпринимательство. 2016. № 12-2. С. 955-964.

11. Демиденко Д.С., Родионов Д.Г., Малевская-Малевич Е.Д. «Цифровой» подход к определению стратегии инновационного производства на предприятии // Фундаментальные исследования. 2018. № 9. С. 53-57.

12. Клечиков А.В., Пряников М.М., Чугунов А.В.Блокчейн-технологии и их использование в государственной сфере // International Journal of Open Information Technologies. 2017. № 12 (5).

13. Косян Н.Г., Милькина И. В. Блокчейн в системе государственных закупок // E-Management. 2019. № 1 (2). 
14. Махноносов Д. В. Электронные торговые площадки как способ повышения качества организации электронной торговли и продвижения товаров и услуг в сети интернет // Инновационное развитие экономики. 2017. № 6. С. 99-105.

15. Прохоров Ю.Н., Самойлов М.Г. Цифровая трансформация и влияние её на развитие конкуренции в сфере закупок в условиях перехода к цифровой экономике // Финансовые рынки и банки. 2019. № 2.

16. Родионов Д.Г. К теоретической оценке государственного и негосударственного регулирования рыночной экономики // Проблемы современной экономики. 2003. № 3-4 (7-8). С. 55-57.

17. Родионов Д.Г., Схведиани А.Е., Бондарев А.А.Цифровая экономика: анализ развития в Российской Федерации // Тенденции развития экономики и промышленности в условиях цифровизации. 2017. Р. 68-93.

18. Сульповар Л., Родионов Д. Проблемы управления государственной собственностью в Российской экономике // Проблемы теории и практики управления. 2012. № 5. С. 52.

19. Фролов А.В. Тенденции и перспективы развития системы государственных закупок в российской Федерации // Вестник науки и образования. 2017. № 4 (28). С. 62-65.

20. ХаКИмов Р.Х. РАЗВИТИЕ ЭЛЕКТРОННОЙ ТОРГОВЛИ КАК ОДНО ИЗ НАПРАВЛЕНИЙ ГОСУДАРСТВЕННОГО РЕГУЛИРОВАНИЯ ТОРГОВЛИ // Научный электронный журнал Меридиан. 2020. № 3. С. 12-14.

21. Проект «Стратегия развития электронной торговли в Российской Федерации на период до 2025 года» [Электронный ресурс]. URL: http://www.consultant.ru/law/hotdocs/51181.html/ (Дата доступа 03.07.2020).

22. Lambert D.M., EnzM.G. Issues in supply chain management: Progress and potential // Industrial Marketing Management. 2017. (62). С. 1-16.

23. Saberi S. [и др.]. Blockchain technology and its relationships to sustainable supply chain management // International Journal of Production Research. 2019. № 7 (57). С. 2117-2135.

24. Заборовская О.В., Дегтерева В.А., Баранова И.В. Тенденции развития сферы услуг в постиндустриальной экономике // Научно-технические ведомости Санкт-Петербургского государственного политехнического университета. Экономические науки. 2008. № 3-1 (58). С. 60-69.

25. Гончарова Н.Л., Заборовская О.В. Мир будущего (индустрия 4.0) и инновационные направления обеспечения занятости пожилых людей в сфере услуг // Российский экономический интернет-журнал. 2018. № 4. С. 22. 